\title{
EMPREENDEDORISMO SOCIAL E COOPERATIVISMO - UMA ANÁLISE DA ATUAÇÃO DA COOPERLIX NO MUNICÍPIO DE PRESIDENTE PRUDENTE-SP
}

Jonathan Lucas Antonio, Heloisa do Nascimento Eustachio Bezerro, Edilene Mayumi Murashita Takenaka.

Universidade do Oeste Paulista - UNOESTE, Curso de Administração, Presidente Prudente, SP. E-mail: antoniojonathanlucas@gmail.com

\section{RESUMO}

Empreendedorismo social é a criação de um negócio com objetivo de resolver problemas sociais e de tornar a sociedade mais inclusiva, sem que se deixe de buscar o lado econômico. O processo de segregação de material reciclável tem um grande potencial de expansão na cidade de Presidente Prudente, SP. Assim, neste estudo, a proposta foi definir o empreendedorismo social e relacionar a formação e atuação de uma cooperativa de trabalhadores em material reciclável, Cooperlix, situada no mencionado município. Para tanto, este estudo foi construído no levantamento de dados encontrados nas literaturas já existentes com a realização de pesquisas bibliográficas por meio de livros, revistas e pesquisas acadêmicas e em sites específicos sobre o tema. Concluímos que o empreendedorismo social e o cooperativismo relacionam-se devido às suas essências e efeitos similares, e ambos têm como o ponto de partida o contexto social e a formação da Cooperlix reitera tais fatos.

Palavras-chave: Empreendedorismo social, Inclusão social, Cooperativismo.

\section{SOCIAL ENTREPRENEURSHIP AND COOPERATIVISM - AN ANALYSIS OF COOPERLIXS ACTIVITY IN THE MUNICIPALITY OF PRESIDENTE PRUDENTE-SP}

\begin{abstract}
Social entrepreneurship is the creation of a business aimed at solving social problems and making society more inclusive, without neglecting to seek the economic side. The process of segregation of recyclable material has a great potential of expansion in the city of Presidente Prudente, in the State of São Paulo. Thus, in this study, the proposal was to define social entrepreneurship and relate the formation and performance of a cooperative of workers in recyclable material, Cooperlix, located in the mentioned municipality. In order to do so, this study was constructed in the collection of data found in existing literature with the accomplishment of bibliographical research through books, magazines and academic research available in the collection of the Unoeste and FCT / Unesp library and in specific sites on the subject. It is concluded that social entrepreneurship and cooperativism are related due to their essences and similar effects, and both have as their starting point the social context and the formation of Cooperlix reiterates these facts.
\end{abstract}

Keywords: Social entrepreneurship, Social inclusion, Cooperativism.

\section{INTRODUÇÃO}

A atividade de empreender é de suma importância para o desenvolvimento econômico, e isto é o que traz riqueza e benefícios para o País.

Muito se tem noticiado sobre a ineficiência dos governos em termos de grandes investimentos em projetos sociais que, com o passar do tempo, mostram-se falhos ou simplesmente esquecidos. Aumentos do desemprego e dos preços de itens básicos do diaa-dia são mais alguns dos problemas sociais enfrentados pela população e pelo poder público.

É sabido que o governo, sozinho, não consegue cumprir com todas as suas obrigações, por isso, a própria liderança pública tem realizado incentivos aos micro e pequenos empresários, a fim de buscar soluções para problemas sociais.

Empreender, da forma convencional como se conhece, contribui positivamente, mas 
superficialmente, com alguns fatores sociais, todavia, um pouco mais a fundo há uma vertente acerca desta atividade, que busca especificamente atacar determinado problema inserido na sociedade, o Empreendedorismo Social.

O empreendedorismo social, também chamado de Terceiro Setor, torna-se mais evidente a cada dia. Entretanto, ainda necessita ser estudado como uma alternativa para a solução de graves problemas sociais que engendram a realidade brasileira.

Essa pesquisa justifica-se devido ao grande potencial de expansão existente na prática de separação de material reciclável, mas que depende não só do praticante, como também do governo e população local e a ação de cooperativas formadas a partir de excatadores de lixo que podem afluir em uma possibilidade de melhoria de qualidade de vida e inclusão social.

A hipótese do presente trabalho é de que uma cooperativa de catadores de materiais recicláveis pode ser considerada um empreendedorismo social e contribui para um ambiente mais saudável e sustentável.

Com isso, questiona-se: As cooperativas de coleta seletiva podem ser consideradas uma forma de empreendedorismo social?

O objetivo do presente trabalho é definir o empreendedorismo social relacionar a formação e atuação de uma cooperativa de trabalhadores em materiais recicláveis, Cooperlix, situada no município de Presidente Prudente-SP.

\section{ASPECTOS METODOLÓGICOS}

Segundo Severino (2007), a metodologia é a explicação minuciosa, detalhada, rigorosa e exata de toda ação desenvolvida no método do trabalho de pesquisa.

Dessa forma, foi utilizado o método de uma pesquisa qualitativa a partir de revisão bibliográfica com levantamento de dados junto à documentação indireta em fontes primárias e secundárias (MASCARENHAS, 2012).

Utilizou-se ainda a prática de pesquisa exploratória por meio da qual se realizou o estudo, a análise, o registro e a interpretação dos fatos sem a interferência do pesquisador, e para isso foi utilizada a revisão teórica tendo como instrumento de pesquisa empregado para a coleta de dados a observação sistemática.

\section{RESULTADOS}

O Empreendedorismo consiste numa atividade em constante evolução, que abrange diversas características em sua forma de ser e por em prática, ações que promovem as economias capitalistas, bem como a inspiração e motivação pessoas das pessoas que nele estão envolvidas.

As palavras empreendedorismo e empreendedor são constantemente utilizadas, e destinam-se a rotular àqueles que criam um negócio de valor para a sociedade, colocando ideias em prática, criando soluções para as necessidades das pessoas, com uma visão abrangente que permite enxergar além do que se vê, independentemente do método por meio do qual se arriscam.

Segundo Biagio (2012, p. 4), "empreendedor é a pessoa que vê oportunidades onde outras pessoas veem somente ameaças".

"Um empreendedor é uma pessoa que imagina, desenvolve e realiza visões" (FILLION, 1999 apud OLIVEIRA, 2012, p. 3).

Dornelas (2014) expõe que "por outro lado, com a disseminação do conceito de empreendedorismo na sociedade, o comportamento empreendedor passou a ser observado com mais atenção em ambientes nos quais antes não se pensava haver empreendedores".

Uma vertente do empreendedorismo tem-se desenvolvido no mundo moderno, o conceito de empreendedorismo social, um conceito ainda em construção, com aspectos de inovação e uma visão social, um modelo de negocio onde visa equilibrar os três pilares da sustentabilidade: resolver problemas sociais, ambientais e socioeconômicos, conforme propõem Mair e Marti (2006), que esta modalidade de empreender um negócio envolve uma junção de meios renovados com a finalidade de proporcionar benefícios que supram as necessidades sociais e com foco na mudança social.

Segundo Cardoso (2015), Ashoka Brasil (2011) e Johnson (2003), o empreendedor social ao invés de procurar uma oportunidade de negócio, busca um problema social e propõe a solução por meio de uma empresa lucrativa criando novas oportunidades de negócios com soluções socioambientais buscando produzir impacto social benéfico.

Dess (1998), aponta cinco características básicas que são relativas ao empreendedor social: (1) adaptar uma missão de gerar e manter 
valor social; (2) reconhecer e procurar novas oportunidades para servir nesta missão; (3) integrar se no processo de inovação, adaptação e aprendizagem continua; (4) agir arrojadamente sem se limitar pelos recursos disponíveis; (5) demonstrar transparência relativamente aos seus parceiros e publico pelos resultados esperados.

Segundo Bornstein e Davis (2010), empreendedores sociais sempre existiram, mas com denominações diferentes, chamados de visionários, santos, humanitários, filantrópicos, ou meramente Lideres, de forma que as atenções eram dadas exclusivamente as suas ações, práticas e corações dispostos a tomar a frente em determinados momentos, solidarizando-se com o sofrimento alheio, tentando de todas as formas encontrar soluções para os problemas.

Em razão de vários entendimentos, Austin (2006) distingue que o surgimento do empreendedorismo social se afere em quatro pontos: (1) falha no mercado: induzido pela falha do empreendedor empresarial; (2) missão: o empresarial apenas visa criação de valor econômico; (3) mobilização de recursos: maior mobilização de recursos e ofertas competitivas; (4) medida de desempenho: empreendedorismo empresarial em medidas de desempenho bem definidas (liquidez, rentabilidade, risco).

Melo Neto e Froes (2002) confirmam apontando que no empreendedorismo social se criam bens e serviços não com intuito financeiro, mas sim com a finalidade de criar soluções para problemas sociais.

Sobre o conceito de cooperativismo, o mesmo não nega o capitalismo, mas enxerga o fenômeno cooperativa como forma de sobrevivência em uma sociedade (BIALOSKORSKI NETO apud RODRIGUES, 2006).

Com isso, o cooperativismo expande-se cada vez mais em mercado competitivo buscando se adaptar a novas práticas, sem perder seu foco principal: a inclusão social. Para Schuneider (2012), a concepção de cooperativismo iniciou-se com a revolução industrial na Europa com o aumento da exploração do trabalho pelos proprietários de indústrias, começando a proliferar a ideia de cooperação, procurando uma organização mais justa e equitativa.

O cooperativismo não é uma ciência, mas uma prática que busca solucionar problemas, sistematizar a reforma da sociedade com inclusão social, distribuição de renda e regularização no mercado.
Cooperativa tem como finalidade satisfazer coletivamente as necessidades socioeconômicas, proporcionando a inclusão social, renda e bem-estar para seus cooperados. (SILVA; PEREIRA; BOTELHO, 2005)

Para ser um associado de cooperativa é necessária uma demanda participativa ativa na condução do empreendimento. Em assembleias são escolhidos os representantes, cargos para o dia-a-dia da cooperativa, pressupondo apenas a representação e não hierarquia.

Segundo Schuneider (2014), as cooperativas são respostas para os problemas causados pelo caos da globalização, geram empregos, inclusão, redistribuição de renda e criação de oportunidades.

Uma cooperativa visa diminuir desigualdades sociais, direcionar seus objetivos a um bem comum, baseada em valores como igualdade, solidariedade, equidade, democracia e responsabilidade social.

\section{COOPERLIX}

Para

Yunus

(2010), no empreendedorismo social as empresas têm como foco proporcionar um benefício social, ao invés de buscarem o lucro para si. Ainda este autor diz que: "Tais empresas pertencem a investidores que buscam benefícios sociais com a redução da pobreza, assistência médica para os pobres, justiça social, sustentabilidade global etc."

Desta forma, podem ser observados objetivos semelhantes aos da cooperativa COOPERLIX (Cooperativa de Trabalhadores de Produtos Recicláveis de Presidente Prudente) que iniciou suas atividades em 2003 através da coleta e triagem dos materiais recicláveis, com o objetivo de organizar o trabalho dos catadores do lixão que havia instalado no município. O funcionamento da cooperativa segue o estatuto das cooperativas que tem como intuito a defesa socioeconômica de seus colaboradores.

A missão da Cooperlix é gerar renda e inclusão social por intermédio do trabalho coletivo visando o crescimento pessoal e o comprometimento com a preservação do meio ambiente, o que contribui com o equilíbrio para os três pilares da sustentabilidade.

\section{DISCUSSÕES}

Quando alguém decide empreender um negócio ele está contribuindo para com a sociedade em geral, pois está gerando emprego, renda, pagando impostos e, direta ou 
indiretamente, realizando sonhos. Este é um agente de mudanças.

Assim, pode-se observar que o empreendedor social é dotado de um senso que lhe permite buscar de formas de atender aos seus colaboradores de maneira que venha a somar valor aos serviços que faz, sendo um bom administrador, não temendo se arriscar (mas de forma calculada) para ajudar as pessoas com as quais sua organização é comprometida, sabendo, porém, discernir entre o que é desejo e o que é necessidade

Desse modo, os empreendedores sociais estarão presentes em instituições sociais de três variedades, como as que prestam serviços sem fins lucrativos, organizações com foco no bemestar, e as que cooperam para ter proteção e benefícios mútuos, como é o caso de associações comerciais, cooperativas, clubes privados e outros.

O cooperativismo veio para balancear as desigualdades provocadas pela exploração de mão de obra. Hoje, o que se vê é cooperativismo como forma de inclusão social ou grupo pequenos que se tornam grandes quando formam uma cooperativa, concorrendo no mercado com as grandes corporações.

\section{CONSIDERAÇÕES FINAIS}

$\begin{array}{ccc}\text { Entende-se que é } & \text { por meio do } \\ \text { empreendedorismo } & \text { que } & \text { ocorre }\end{array}$ desenvolvimento da economia. Este tem diversas vertentes e uma delas é o empreendedorismo social, que é caracterizado por ter ênfase na solução dos diversos tipos de problemas sociais.

Inseridos nesta vertente, podem ser encontrados o cooperativismo e as cooperativas. O primeiro com a finalidade de inclusão social, e o segundo tem como propósito satisfazer as necessidades de um coletivo, gerar renda e proporcionar bem- estar.

Assim, a Cooperlix (Cooperativa de Trabalhadores de Produtos Recicláveis de Presidente Prudente), promoveu a inclusão social dos catadores clandestinos que realizavam a segregação de material reciclável no aterro sanitário do município, sem quaisquer garantias de segurança, remuneração adequada, saúde e dignidade.

Mesmo havendo esta mudança, ainda se faz necessária a participação ativa da comunidade local em separar estes objetos, pois é deles que emana o sustento dos cooperados e cooperativa. $O$ governo municipal também tem as responsabilidades de contribuir na conscientização dos munícipes e fornecer os recursos necessários para a cooperativa realizar o do processo no todo. Todos unidos beneficiam-se com a melhora da qualidade de vida.

\section{REFERÊNCIAS}

ASHOKA BRASIL. Empreendedorismo social. 2. ed. Porto Alegre: Bookman, 2011. 202 p.

AUSTIN, J., STEVENSON, H.; WEI-SKILLERN, J. Social and commercial entrepreneurship: same, different, or both? Entrepreneurship Theory and Practice, v.30, n.1, p.1-22, 2006. https://doi.org/10.1111/j.1540$\underline{6520.2006 .00107 . x}$

BIAGIO, A. L. Empreendedorismo: construindo seu projeto de vida. 1. ed. 2012.

BORNSTEIN, D.; DAVIS, S. Social entrepreneurship: what everyone needs to know. New York: Oxford University Press, 2010.

CARDOSO, G. Mude você o mundo. 1. ed. São Caetano do Sul: Lura Editorial, 2015.

DORNELAS, J. Empreendedorismo: transformando ideias em negócios. 6. ed. São Paulo: Empreende, Atlas, 2014.

JOHNSON, S. Young social entrepreneurs in Canada. 2003. Disponível em: http:// www.bus.ualberta.ca/ccse/Publications.

MAIR, J.; MARTÍ, I. Social Entrepreneurship Research: A Source of Explanation, Prediction and Delight. Journal of World Business, v. 41, p. 3644, 2006.

https://doi.org/10.1016/j.jwb.2005.09.002

MELO NETO, F. P.; FROES, C. Empreendedorismo Social: a transição para a sociedade sustentável. Rio de Janeiro: Qualitymark, 2002.

OLIVEIRA, E. M. Empreendedorismo social no Brasil: atual configuração, perspectivas e desafios - notas introdutórias. Rev. FAE, Curitiba, v.7, n.2, p.9-18, jul./dez. 2004.

SCHNEIDER, J. O. A doutrina do cooperativismo: análise do alcance, do sentido e da atualidade dos seus valores, princípios e normas nos tempos 
atuais. Cadernos De Gestão Social, Salvador, v.3, n.2, p.215-273, 2012.

SEVERINO, A.J. Metodologia do trabalho científico. 23. ed. São Paulo: Cortez, 2007.

SILVA, E. A.; PEREIRA, J. R.; BOTELHO, M. I. V. A Organização Cooperativa e seus Princípios Democráticos. Organizações Rurais

Agroindustriais, v.7, n. 2, p. 135-147, 2005.

YUNUS, M. Um mundo sem pobreza: a empresa social e o futuro do capitalismo. 1. ed. 2010.

Recebido para publicação em 10/04/2018

Revisado em 05/06/2018

Aceito em 18/06/2018 